\title{
Juventude, educação, sonhos, desejos e expectativas: experiência da Casa Familiar
}

\section{Rural no Maranhão}

Youth, education, dreams, wishes and expectations: experience of a Rural Family Home in

\section{Maranhão}

\section{Juventud, educación, sueños, deseos y expectativas: experiencia de la Casa Familiar Rural -}

\section{Maranhão}

Cristina Maria Douat Loyola

ORCID: https://orcid.org/0000-0003-2824-6531 Universidade CEUMA, Brasil

E-mail: crisloyola@hotmail.com

Sebastião Rocha

ORCID: https://orcid.org/0000-0001-8730-6106 Centro Popular de Cultura e Desenvolvimento, Brasil

E-mail:tiaorocha@cpcd.org.br

Claudia Barbastefano Monteiro

ORCID: https://orcid.org/0000-0002-3150-7424

Universidade Federal do Rio de Janeiro, Brasil

E-mail:claudia.ipub@gmail.com

Ednalda Aparecida Santos

ORCID: https://orcid.org/0000-0002-3526-6744 Centro Popular de Cultura e Desenvolvimento, Brasil E-mail: ednalda@cpcd.org.br

Maria da Luz Sousa Estácio

ORCID: https://orcid.org/0000-0002-5246-4339

Casa Familiar Rural Padre Josino Tavares de Bom Jesus das Selvas, Brasil

E-mail: daluznatureza@gmail.com

Ligia Costa Leite

ORCID: https://orcid.org/0000-0003-3168-2799

Universidade Federal do Rio de Janeiro, Brasil E-mail: ligia.cleite@gmail.com

\section{Resumo}

Este artigo objetivou conhecer sonhos e expectativas no processo de construção de identidades para a vida adulta de adolescentes, estudantes de uma Casa Familiar Rural, Bom Jesus das Selvas (CFR/BJS), no Estado do Maranhão, Nordeste do Brasil. A população-alvo envolveu de 30 jovens (coletando narrativas em entrevistas semiestruturadas), a equipe técnica da Casa e os pesquisadores adotaram o enfoque da pesquisa-ação. Os dados obtidos foram examinados pela abordagem da análise temática, a partir de dois eixos: Aprendendo a sonhar dentro da CFR e Aprendendo a viver fora da CFR. Foi possível concluir que a metodologia de educação popular para a cidadania, respeitando a cultura local, desenvolvida pela ONG parceira, com a meta de criar um Centro de Excelência em Educação para o Jovem do Campo, gerou uma experiência de inovação e transformação social para desenvolvimento comunitário sustentável. Conseguiu superar a fragmentação de conteúdo existente na prática rural e articular a educação com a vida dos alunos, seus desejos e as perspectivas futuras, estabelecendo metas de autossuficiência hídrica, alimentar e renda.

Palavras-chave: Pedagogia da alternância; Educação popular; Adolescentes; Educação rural; Ensino médio; Educação do campo.

\begin{abstract}
This article aimed to discover dreams and expectations in the process of building identities for the adult life of adolescents, students of a Rural Family House, Bom Jesus das Selvas (CFR/BJS), in the State of Maranhão, Northeastern Brazil. The target population consisted of 30 young people (collecting narratives in semi-structured interviews), the Casa's technical team and the researchers adopted the action research approach. The data obtained were examined using the thematic analysis approach, based on two axes: Learning to dream within the CFR and Learning to live outside the CFR. It was possible to conclude that the methodology of popular education for citizenship, respecting the local culture, developed by the partner NGO, with the goal of creating a Center of Excellence in Education for Young People in the Country, generated an experience of innovation and social transformation for development
\end{abstract}


sustainable community. It managed to overcome the fragmentation of content existing in rural practice and articulate education with the lives of students, their desires and future perspectives, establishing goals for water, food and income self-sufficiency.

Keywords: Alternation pedagogy; Popular education; Teenagers; Rural education; High school; Countryside education.

\section{Resumen}

Este artículo tuvo como objetivo descubrir sueños y expectativas en el proceso de construcción de identidades para la vida adulta de adolescentes, estudiantes de una Casa de Familia Rural, Bom Jesus das Selvas (CFR / BJS), en el estado de Maranhão, noreste de Brasil. La población objetivo estuvo formada por 30 jóvenes (recogiendo narrativas en entrevistas semiestructuradas), el equipo técnico de la Casa y los investigadores adoptaron el enfoque de investigaciónacción. Los datos obtenidos fueron examinados utilizando el enfoque de análisis temático, basado en dos ejes: Aprender a soñar dentro del CFR y aprender a vivir fuera del CFR. Se pudo concluir que la metodología de educación popular para la ciudadanía, respetando la cultura local, desarrollada por la ONG socia, con el objetivo de crear un Centro de Excelencia en Educación para Jóvenes del País, generó una experiencia de innovación y social transformación para el desarrollo de una comunidad sostenible. Logró superar la fragmentación de contenidos existente en la práctica rural y articular la educación con la vida de los estudiantes, sus deseos y perspectivas de futuro, estableciendo metas para la autosuficiencia hídrica, alimentaria y de ingresos.

Palabras clave: Pedagogía de la alternancia; Educación popular; Adolescentes; Educación rural; Escuela secundaria; Educación rural.

\section{Introdução}

Este trabalho tem como objetivo conhecer desejos, sonhos e expectativas da juventude estudante da Casa Familiar Rural Padre Josino Tavares de Bom Jesus das Selvas (CFR-BJS), no Estado do Maranhão, nordeste do Brasil, para analisar a pedagogia da alternância como um caminho educacional para jovens do campo e um meio de aprendizagem da agricultura familiar. Este método funciona em dois cenários que possibilitam os jovens a juntar dois mundos: o do ensino teórico regular de nível médio e o da prática profissional, que se alternam entre períodos de normas e regras dentro da escola e de trocas com o município sede e com as famílias para transmissão de conhecimentos adquiridos e de práticas desenvolvidas na CFR.

Existem poucos estudos no Brasil sobre a educação e o modo de viver nas comunidades rurais, principalmente sobre as juventudes brasileiras que vivem nessas regiões. Há poucos dados de como vivem e sobrevivem financeiramente, quais seus sonhos e desejos, entre outros aspectos. Mesmo sendo considerado um grupo social vulnerável, protegido por leis federais que garantiriam direitos básicos dentro da diversidade étnica do país, nem sempre tem acesso a tais benefícios. Os riscos e a desproteção são agravados por determinações socioeconômicas decorrentes da marginalização existente, especialmente quando saem dos territórios originários. Portanto, considera-se importante compreender como os alunos da CFR-BJS vivem, sonham e agem neste ambiente escolar e quando estão em outros espaços socioculturais, como o aprendizado e a vivência na escola impacta suas singularidades, de modo a divulgar esses costumes e cultura para outras regiões.

A CFR-BJS foi fundada em 2008 a partir de uma Associação de Assentados Rurais e utilizava a pedagogia da alternância, ou seja, os alunos alternavam 15 dias na escola e 15 dias em casa para praticar o que haviam aprendido. Nesta Casa estavam matriculados 71 jovens provenientes de 23 comunidades do entorno, que iniciavam o primeiro e segundo anos do ensino médio.

Em 2016, o Centro Popular de Cultura e Desenvolvimento / CPCD , uma ONG que desde 1984 atua com educação popular em projetos inovadores de transformação social associados ao desenvolvimento comunitário sustentável, propôs uma parceira com esta CFR, tendo como instrumento de trabalho e matéria-prima a cultura local (Parreira, 2014; Rocha, Coutinho, Monteiro, \& Loyola, 2021). De imediato, ao observar as condições insalubres da escola (sem saneamento básico e condições mínimas de higiene), a precariedade de recursos (repassados por prefeituras ao redor e famílias dos alunos), número insuficiente de educadores (cinco dos 14 professores previstos), a ONG iniciou um trabalho de mobilização social, para criar um Centro de Excelência em Educação do Jovem do Campo e aprofundar as tecnologias de permacultura e bioconstrução. Para tal obteve 
apoio financeiro da Porticus (fundação holandesa) para execução da agenda e da Universidade Ceuma para entrevistar o corpo social, registrar e analisar a concepção e processo vivido.

Tendo como ponto de partida a Carta da Terra (redação final 2000) adotada pelo CPCD como premissa conceitual, que faz uma convocatória à adoção dos princípios integradores da ecologia. Essa pratica planetária foi introduzida nas atitudes diárias, integradas a cada uma das disciplinas curriculares, desde a física e biologia até a história, buscando uma integração orgânica na trilogia "ensino-pesquisa-extensão" da CFR.

Assim ela se tornou a mais importante dimensão dentro do Plano de Trabalho e Avaliação / PTA (tecnologia desenvolvida pelo CPCD) elaborado para o Centro de excelência fazendo com que a filosofia da educação do campo, imbuída de valores ambientais, perpassasse todas as disciplinas do currículo, uma estrutura integrada e coerente para desenvolver os dois programas do CPCD - "Meu lugar é aqui" e "Cuidando dos tataranetos". Programas, currículos educacionais, ensino e aprendizado aliados como pratica de um mundo mais justo, sustentável e pacifico. Essa abordagem integrada e integradora enfatiza os diferentes desafios enfrentados pela CFR, fazendo conexões com as outras dimensões e disciplinas para a autonomia hídrica, alimentícia e a sustentabilidade econômica.

A convergência da pedagogia da alternância e a plataforma de desenvolvimento sustentável proposta pelo CPCD alavancou uma possibilidade poderosa de reverberação e disseminação dos princípios e práticas do PTA, uma vez que a escola atendia muitos jovens e recebia grandes demandas das diversas comunidades rurais que compõem os municípios atendidos, num formato propicio a ser replicado em toda escola do campo - CFRs, EFAs

O primeiro desafio foi feito aos alunos e professores: "plantar 10 mil árvores em BJS em 10 minutos" (Rocha, 2018). Essa atividade mobilizou todos e, sobretudo, responsabilizou os discentes da CFR a preparar as 10 mil mudas para entregar aos moradores da cidade. Semeando a ideia de que era possível mudar a realidade, a ação possibilitou o resgate da autoestima dos estudantes, que se tornaram agentes de transformação socioambiental. Esta meta foi alcançada quando mais de 9 mil pessoas plantaram mais de 10 mil árvores, em menos de 10 minutos, gerando um efeito extraordinário.

Nos três anos subsequentes, a ONG (o Centro popular de Cultura e Desenvolvimento desenvolveu atividades estratégicas em direção à excelência. Para isso foram concretizadas diversas oficinas de permacultura e bioconstrução para caixa de captação de água da chuva, banheiros secos para a escola e georreferencia de dez locais prioritários para intervenção socioambiental. Também foi construído um galpão para semear mudas, plantio e manutenção de horta para produção de alimentos orgânicos e criação de pequenos animais, atendendo aos aspectos da formação e da alimentação diária na CFR. Por fim, capacitar alunos como agentes sociais comunitários para o desenvolvimento sustentável.

Ao final desses anos, utilizando a pesquisa-ação, como parte do aprender-fazendo, estimulou-se os participantes a criar metas para a escola, como captar água e produzir integralmente seu alimento, conquistando, independência nesses quesitos.

A educação popular do CPCD assumia que ensinar "é mobilizar o desejo de aprender" (Gadotti, 2003, p. 54), de modo a potencializar os alunos a encontrar respostas e soluções para questões presentes no cotidiano, com outros padrões de formação e sem abandonar as relações familiares:

[...] a "Pedagogia da Terra" [...] é apropriada para esse momento de reconstrução paradigmática, apropriada à cultura da sustentabilidade e da paz. [...] Ela se fundamenta num paradigma filosófico ${ }^{1}$ emergente na educação que propõe um conjunto de saberes/valores interdependentes. Entre eles podemos destacar: Educar para pensar globalmente [...]; educar os sentimentos [...]; ensinar a identidade terrena como condição humana essencial [...]; formar para a consciência planetária [...]. (Gadotti, 2003, p.59).

\footnotetext{
${ }^{1}$ Entre os principais representantes desse paradigma podemos citar: Paulo Freire, Leonardo Boff, Sebastião Salgado, Sebastiâo Rocha, Boaventura de Souza Santos, Milton Santos, Fritjop Capra, Edgar Morin.
} 
Brandão amplia este conceito ao afirmar que "todos os dias misturamos a vida com a educação" (2019, s/p) e o processo no campo é permanente na vida. Segundo o autor, a educação sustentável, conscientizadora e emancipadora, precisa romper com o mundo capitalista e urbano, que não é sustentável. O currículo da escola rural ainda é um fragmento urbanoide do ensino nas cidades (Brandão, 1984), com uma ruptura do ensino com a terra. O ideal de alcançar a valorização social do campo e do jovem que ali vive e trabalha, ainda precisa ser atingido.

Assim, para identificar e analisar as percepções das vivências e anseios de estudantes inseridos na CFR-BJS, buscou-se descrever a experiência pedagógica ali desenvolvida e como esta atingia os discentes, de modo a examinar suas perspectivas de vida no presente e para o futuro.

\section{Pedagogia da alternância}

A pedagogia da alternância surge em 1935, na França, com a fundação da primeira Maison Familiale Rurale - MFR (Granereau, 1968), como um método de educação profissional, para atuar com o ensino-aprendizagem na área rural em dois espaços: na propriedade familiar e na escola rural de ensino médio regular. No Brasil, as Casas Familiares Rurais iniciam suas atividades na década de 1970 (Nosella, 2014), assentando-se se sobre quatro pilares divididos entre meios e fins. Os meios são os rodízios entre o espaço escolar e a moradia, articulando alunos/familiares/profissionais. Os fins orientam os meios para promoção integral dos participantes, criando projetos pessoais e coletivos de desenvolvimento socioeconômico, humano, político etc. (Gimonet, 2007; Sinhoratti, 2015).

Nesse sistema, as famílias rurais podem manter seus filhos no ensino médio regular sem criar uma cisão entre o estudo teórico do currículo oficial e seus próprios saberes, aprendidos e apreendidos no cotidiano do território onde vivem. Conforme alternam a permanência entre a escola e a casa, a cada 15 dias, os alunos implementam junto às famílias práticas agrícolas aprendidas e, simultaneamente, levam ao curso os conceitos de seu meio rural. Assim, sistematizam e articulam esses conhecimentos:

A vivência do aluno no sistema [...], a semana ou quinzena em que ele fica no meio escolar, tem como pressuposto que a vida tem o valor de educação, de reflexão, de formação. Ou seja, a ruptura, o distanciamento do meio de vida constitui uma estratégia educativa para propiciar aos jovens uma melhor percepção e, consequentemente, uma reflexão sobre sua realidade, estimulando uma nova visão do contexto familiar, da propriedade e das questões cotidianas presentes no seu meio socioeconômico, [como] objetos da formação e de seus projetos de intervenção. (Silva, 2009, p.283).

O processo da alternância é um ritmo em três tempos: primeiro, no meio familiar, profissional e social, desenvolvendo experiência, observação, investigação e análises (saberes empíricos); segundo, na CFR, para formalização-estruturação e conceitualização dos saberes teóricos, formais e curriculares do ensino médio; terceiro, na aplicação-ação e experimentação (saberes-ações) para unir o conhecimento nesse processo (Gimonet, 2007).

\section{Juventude}

A juventude é um período de transição de uma fase do desenvolvimento humano que tem início na puberdade, sendo marcada por um status ambíguo entre a infância e a idade adulta. A transição juvenil caracteriza-se por um processo de socialização e atribuição de papéis sociais característicos, com direitos e deveres específicos, mais amplos do que os das crianças e não tão completos quanto os dos adultos (Troian, Dalcin, Oliveira, \& Troian, 2011; Weisheimer, 2005). De acordo com o Estatuto da Juventude (Brasil, 2013), compreende idades entre 15 e 29 anos, e representa quase 1/4 da população total, segundo IBGE (Brasil, 2020).

Ser jovem é viver um período de mudanças particularmente rico em possibilidades desestabilizadoras, independentemente do grupo socioeconômico. É um momento de definições diversas no campo sexual, profissional e familiar, 
lançando dilemas, nem sempre viáveis de resolver. Para constituir sua identidade adulta, o jovem se expõe a riscos e a crise normal da adolescência pode se ampliar, precipitando descaminhos na vida e na saúde (Saggese, E.; Leite, 2011). Nesse período ele se debate com temas fundamentais para sua identidade pessoal e social, seu projeto de vida futuro, o que pode levar a transtornos patológicos leves ou graves. Saggese diferencia:

Adolescer e adoecer são, nas práticas e nas teorias do campo da saúde, frequentemente confundidos. Se adolescer significa, em termos etimológicos, crescer, brotar, fortificar-se, o que acontece quando esse processo enfrenta empecilhos sociais relevantes? Entramos no terreno do adoecer, debilitar-se, amargurar-se, afligir-se. (2020, p.7).

Contudo, existem diferentes juventudes brasileiras, que não são homogêneas em suas etnias, situações socioeconômicas, formas de viver/sobreviver, desejos e sonhos. As que moram em áreas rurais vivem uma complexa rede de relações sociais ao se locomover de seu território para "outro mundo", as cidades, onde há outros códigos de convivência, com espaços e inserções sociais distintos. Essas diferenças podem gerar dilemas, apresentar incertezas ou ambivalências entre seguir suas raízes culturais, religiosas e de costumes, que desejam preservar, ou caminhar em direção a outras culturas (urbana pós-moderna), para se inserir e construir seus projetos de futuro.

Nesse sentido, a escola tem um papel fundamental, não apenas para escolaridade, espaço de lazer e convivência, mas para a construção de identificações e projeções para o futuro, que podem ir além do trabalho rural, a partir da perspectiva, sonho e desejo dos jovens dessas comunidades (Pizzinato, Petracco, Hamann, Cé, \& Rosa, 2017).

\section{Metodologia}

A pesquisa teve o enfoque qualitativo, com a abordagem da pesquisa-ação abrangendo alunos, equipe da CFR e pesquisadores. Foram realizadas entrevistas semiestruturadas com 30 estudantes na faixa etária entre 16 a 22 anos, sendo 19 homens e 11 mulheres. A maior parte estava cursando o terceiro ano do ensino médio. O objetivo do estudo foi procurou avaliar percepções e opiniões de adolescentes a respeito de como vivem, sentem e pensam (Minayo, 2016).

Estudar nesta instituição nem sempre foi a primeira opção para maior parte dos alunos, porém fatores indiretos propiciavam a entrada na CFR-BJS, entre eles: ausência de escolas, de professores ou de aulas nas escolas existentes na comunidade, imposição dos familiares e dificuldades de locomoção para outros locais, pois a residência era mais próxima. Quase todos moravam com pais, avós ou tios, cuja ocupação concentrava-se predominantemente no campo (agropecuária). O relacionamento dos discentes era considerado bom em casa, com os pais/responsáveis eram mencionados como trabalhadores, companheiros e incentivadores. A quantidade de irmãos nascidos dos mesmos pais variava entre três e nove, sendo a maioria mulher. Parte dos irmãos, em função de trabalho, casamento ou curso superior, havia se mudado para outro estado, cidade ou município próximo. Apesar das brigas, chateações e "puxões de orelha", comuns entre irmãos, a relação era referida como boa e tranquila.

A entrevista semiestruturada abordou temas relativos às vivências na Casa; problemas enfrentados no local; sonhos e expectativas; relação com a família e com outras instituições; pontos ligados ao trabalho/profissionalização; atividades culturais e religiosas; e desejo/escolha de permanência ou não no campo. Estas foram gravadas e posteriormente transcritas. Dos dados obtidos foram selecionadas as respostas mais significativas e que possibilitassem entender a realidade por eles vivida.

O material coletado foi examinado pela abordagem da análise temática (Braun \& Clarker, 2014), dentro da perspectiva reflexiva, para encontrar núcleos de sentido que articulassem as narrativas das entrevisas com a pesquisa-ação dentro dos objetivos propostos. Os temas foram definidos a partir de dois eixos que surgiram do material coletado: Aprendendo a sonhar dentro da CFR e Aprendendo a viver fora da instituição. O primeiro eixo dividiu-se em: Normas e rotinas no cotidiano da Casa; 
Metodologia do ensino e conteúdo didático; Laços e vínculos construídos. O segundo eixo apresentou a ambiguidade e a incerteza diante da escolha de migrar ou não para a cidade, aprofundar os estudos e cursar o nível superior.

Este estudo, inserido no mestrado de Gestão de Políticas e Serviços de Saúde da Universidade CEUMA, foi realizado seguindo as normas da resolução 422/12 do Conselho Nacional de Saúde. Os sujeitos foram informados a respeito da importância e do objetivo da pesquisa para que eles ou seus responsáveis assinassem o Termo de Consentimento Livre e Esclarecido. O projeto foi aprovado pelo CEP da Universidade, com número de parecer CEUMA 2.308.282.

\section{Resultados e Discussão}

\subsection{Aprendendo a sonhar dentro da CFR-BJS}

\section{Normas e Rotinas no cotidiano da Casa}

As atividades em conjunto eram as que os alunos mais gostavam, juntamente com a vivência de aplicar os aprendizados e o ensino de conhecimentos teóricos que recebiam nas aulas, na prática do dia a dia. Os trabalhos de manter limpeza da Escola, realizados em grupo, levava-os a assumir um coletivo acolhedor que zelava pelos laços de afetividade, solidariedade e respeito que se formavam, como afirmado abaixo:

Porque a gente compartilha as coisas juntos, a gente dorme junto, a gente sonha os mesmos sonhos, né? Então é bom demais, gente (risos). Só é ruim no final, que às vezes a gente termina o curso, aí cada um vai pra um lado, mas aqui a gente se sente... é uma família, muito bom. $\left(\right.$ EM12) ${ }^{2}$

Por outro lado, havia dificuldades pautadas nas excessivas regras como namorar e sair sem avisar, além de punições com suspensão ou expulsão por uso de álcool e cigarro. As penalidades variavam de acordo com a gravidade da infração e iam desde suspensão até realização de afazeres na Casa sozinho, como passar a semana lavando vasilhas e panelas, limpar o pátio durante todo período da alternância.

Qualquer aluno possuía permissão para reclamar ou pedir algo, podendo solicitar assembleias ou reuniões com os coordenadores para discutir assuntos ou problemas. $\mathrm{O}$ vínculo entre os profissionais e eles baseava-se na amizade e no respeito (sem muita intimidade). Cada um tinha consciência de seus limites e tudo era mantido dessa forma:

Legal é assim a gente tem a hora de brincar e a hora do trabalho [...] eles têm o profissional deles, né? Aí, eu sei a hora (EM5)

[...] eu não sou muito de ficar conversando com eles não, a gente conversa mais quando estamos na sala de aula, quando a gente tem alguma dúvida lá fora a gente pergunta, não é relação igual [quando] a gente tá conversando com os amigos (EM17).

Não havia nenhum tipo de preconceito, seja por parte dos alunos, seja por parte de professores ou funcionários, nem favorecimento ou diferença no tratamento entre discentes e docentes. Todos respeitavam-se igualmente, sendo os direitos e deveres iguais para todos:

Aqui o que é ofertado pra um é ofertado pra todos, da mesma forma. (EM22)

\footnotetext{
${ }_{2}^{2}$ Para garantir a privacidade e o anonimato dos participantes, os nomes foram substituídos por siglas de Ensino Médio (EM) seguido pelo número da entrevista.
} 
Ainda assim, regras e punições eram seguidas e quase nunca desrespeitadas, pois os alunos, de modo geral, gostavam de estar ali.

\section{Metodologia do Ensino e Conteúdo Didático}

Em decorrência de idas e vindas entre o meio familiar e o escolar, devido à pedagogia da alternância utilizada, a formação teórica era processada em conjunto com a prática: o meio escolar proporcionava o conhecimento técnico-científico e o meio familiar viabilizava sua aplicação em condições reais e específicas de cada unidade doméstica produtiva. A escolarização no nível médio de forma gratuita era integrada à formação/profissionalização para atuar no trabalho no meio rural, com o objetivo de educar para o exercício da cidadania e, de preferência, a permanência em suas comunidades de origem. Desse modo, a instituição gerava a possibilidade de viabilizar o desenvolvimento de uma agricultura local sustentável e solidária, com técnicas de produção agropecuária adequadas, promovendo transformação, participação em cooperativas e comercialização dos produtos, valorizando a cultura local.

A escolaridade seguia os Parâmetros Curriculares Nacionais para o ensino médio (Brasil, 2009). Como essas diretrizes foram geradas pelo Ministério da Educação para todo o país e não planejadas ao contexto da CFR-BJS vinculadas à realidade local, os alunos argumentaram que deveria haver um equilíbrio maior entre teoria e prática, pois os trabalhos braçais de limpeza e manutenção, que eram obrigatórios, bem como o cuidado com as plantações e os animais, junto com o excesso de disciplinas obrigatórias para o ensino regular, apresentavam algumas dificuldades para formar técnicos com mais qualidade e confiança, como narrou abaixo um aluno:

[...] ela poderia tá formando técnicos assim com mais prática, menos teoria [...], para viagens práticas, mas é pouco. Então eu acredito que o técnico, quanto mais ele é formado na prática, eu acredito que mais prática [...] aí teríamos técnicos com mais qualidade [...] Com certeza a gente seria formado com mais confiança [...]. (EM4)

Deste modo, para atender ao objetivo institucional, o CPCD ajudou a compor uma ordem curricular e operacional própria para formação técnica e qualificação do trabalho no campo, com o aumento da instrução e a capacitação profissional, ajudando o aluno no cotidiano de Casa dentro de sua cultura. Essa parte profissionalizante tinha como fim a habilitação de conhecimentos em ação (aprender-fazendo), gerando significado para a vida, através de práticas cognitivas, ocupacionais e socioemocionais, como atitudes e valores para o trabalho e cidadania do educando.

O currículo abarcava curso técnico em agropecuária e outras temáticas, como de avicultura; suinocultura; caprinocultura; bovinocultura; piscicultura; plantação de árvores frutíferas; horticultura e, em um conteúdo transversal, aulas de inglês, artes (teatro, dança, música, artes plásticas) e informática/computação. Ainda, por sugestão dos educandos, esse foi ampliado com aulas práticas de temas como: criação de outros animais; laboratório para experiências inovadoras; curso de agroecologia específica; curso mais avançado que o técnico agrônomo; reformas arquitetônicas e elétricas; além de esportes diferentes, como lutas. Além disso, eram oferecidas oficinas de preparação para educador social para desenvolvimento socioambiental.

Ao perceberem que era viável fazer uma educação com sentido e pertinência, os professores começaram a romper a própria resistência em superar o currículo tradicional. Assim, seguindo a pesquisa-ação foram sugeridas mudanças e as disciplinas oficiais passaram a ser ministradas à noite (Educação e Território, 2018). Este currículo foi reconhecido e aprovado pelo Conselho Estadual de Educação do Maranhão (CEE/MA).

Com a participação do CPCD e o desejo de transformar a CFR em um "Centro de Excelência em Educação no Campo", foram colocadas em prática metas para três anos, de modo a coincidir com o período do ensino médio. A do primeiro ano era autonomia hídrica em interface com os conteúdos do currículo escolar de professores de física e matemática, que compartilhavam os conhecimentos técnicos necessários para a construção de caixa d'água e outros equipamentos. Conforme afirmou o presidente 
da ONG: "O resultado foi a autossuficiência hídrica da escola. Agora, já viram até que é possível captar a água da estrada e fazer um lago na região. Já estão discutindo como criar peixes nesse lago" (Rocha, 2018). As metas para o segundo e o terceiro anos para atingir a excelência do projeto, tinham como finalidade excluir comidas enlatadas e não depender de merenda das prefeituras, direcionando a escola a produzir seu próprio alimento e vender a produção excedente. Com esses propósitos estabelecidos, todos os planos dentro e fora de sala de aula foram reposicionados e trabalhados para que fossem cumpridos, de maneira a conseguir superar a fragmentação de conteúdo existente na prática rural e articular a educação com a vida dos alunos (Rocha, 2018).

Desse modo, a CFR-BJS adquiriu autonomia hídrica e alimentar, aumentando sua independência em relação à inconstância de financiamento das prefeituras e, simultaneamente, ensinando os alunos a produzir a mesma autonomia no entorno da instituição e em suas próprias casas e comunidades. Percebeu-se um grande sentimento de gratidão, conforme expresso abaixo:

Como aluna eu aprendi... a... a dignidade de ser camponês, a não renegar a minha identidade, porque eu morava no campo, mas a gente sempre vive de espécie, porque as escolas, elas não ensinam esse tipo de respeito, de ética que a gente tem que ter, elas ensinam pra gente trabalhar pro capitalismo, entendeu? E aqui eu aprendi a gostar da minha identidade, a não ter vergonha [...]. (EM8)

[...] estou contribuindo nas ações socialmente, estou passando os meus conhecimentos para as outras pessoas, não presa aqui na escola... como a gente vai nas comunidades, participa de várias atividades sociais junto com as pessoas, então hoje eu me considero uma educadora social. (EM15)

Um aluno descreveu que era fraco em conteúdo, tanto escolares quanto agrícolas, antes do início de sua aprendizagem nesse local, quando pôde superar sua deficiência. Outro relatou o empoderamento gerado ao entrar na CFR:

Ah, eu sofri muito preconceito, [diziam] que eu era doido [...]. Eu respondia: doidos são vocês que não têm objetivo na vida. [...] Se eu plantar, produzir muita árvore, para eu plantar e as outras pessoas plantarem, a gente vai ter uma capacidade de ter uma vida melhor, tanto para nós quanto para as futuras gerações. É por isto que eu impregnei essa [...] se tornou uma arte na minha vida. (EM9)

Ou seja, a instituição passou a agregar valores morais aos estudantes, sendo considerada "um presente de Deus" e uma grande oportunidade de mudar/melhorar de vida, como uma porta de entrada para realização de sonhos.

\section{Laços e Vínculos Construídos}

A convivência em internato propiciou uma melhor integração entre monitores e alunos, gerou vínculos e laços de confiança e de amizade. A participação em grupo nas atividades de limpeza e nas refeições criou organização, além de produzir inspiração e admiração entre todos. Isso fez com que alguns profissionais fossem considerados como pais sociais de alguns estudantes, pois eram seus incentivadores e inspiradores.

Da mesma forma, mas comunidades onde viviam, os adultos eram um fator de sustentação e apoio na execução de projetos técnicos, pois as relações construídas entre escola-família na perspectiva pedagógica de alternância eram reafirmadas nas residências. A constituição de vínculos nos dois ambientes era ampliada, uma vez que a família participava de muitas atividades no espaço escolar, bem como na avaliação dos conteúdos recebidos por seus filhos e nos temas mais específicos que eles gostariam de aprofundar. Por outro lado, a presença dos monitores nas visitas às moradias também auxiliava os jovens na execução de projetos, reformulando planejamentos e práticas no manejo da permacultura e aumentando as trocas de conhecimento em um processo de constituição de confiança entre todos os atores.

Ao saírem da CFR-BJS, os alunos aplicavam o que aprendiam com a família e comunidade, mas também aproveitavam para rever amigos, praticar a fé religiosa, entre outras atividades de lazer, tomar banho em rios e ir em noites culturais, como 
fazer esportes, ver televisão, receber visitas, ir a encontros de jovens. Em casa, ficavam alegres ao verem que eram requisitados para cuidar de plantações de vizinhos e amigos, demonstrando a aplicabilidade de seu aprendizado e o desejo de continuar na área rural para ajudar os outros:

Às vezes, tem vezes que eu chego aqui já mãe já fala "ó, veio alguém te procurar aqui pra te [...] ir olhar uma horta dela, um canteiro, uma coisa, um porco que passa mal, uma galinha que tá lá doente” [...]. Eu gosto muito de mexer assim [...] alguns saem de lá e vai pra cidade, né? Aí fica lá se divertindo, tudo e tal. Não, eu gosto de sair de lá e vim pra cá, que eu gosto de mexer com o que envolve assim o meio rural. (EMI4)

Porque estou contribuindo nas ações socialmente, estou passando os meus conhecimentos para as outras pessoas, não presa aqui na escola... como a gente vai nas comunidades, participa de várias atividades sociais junto com as pessoas, então hoje eu me considero uma educadora social. (EM5)

Os encontros com colegas e professores fora da CFR eram raros, mas a relação permanecia a mesma. Em ambientes exteriores à escola, a maneira do tratamento utilizada era fraternal, conforme disse um entrevistado:

Ah quando nós tá fora da escola é bom demais (risos), todo mundo se trata como irmão, pode tá em qualquer lugar que a pessoa vem falar com a gente." (EM28)

O aprendizado também plasmava uma formação humanista na medida em que reconheciam ter adquirido tolerância na capacidade de convivência com outros, solidificando laços de amizade que permaneciam, independente de novos cenários sociais. Havia também um aprendizado a respeito do cuidado de si e do ambiente de moradia.

\subsection{Aprendendo a viver fora da Casa}

Além do diploma de conclusão do ensino médio, o ensino teórico-prático deu aos jovens a oportunidade de decidir entre permanecer no campo ou migrar para a cidade, o que podia significar, conforme argumenta Carneiro (1998), ir ao encontro da modernidade, rompendo com os laços de dependência e proteção familiar. "[...] É um dos primeiros passos para construir sua individualidade, buscar a realização de sonhos [...]”. (Sinhoratti, 2015).

A ida para as áreas urbanas não estava, necessariamente, relacionada à continuidade dos estudos, pois o nível educacional dos filhos de pequenos produtores rurais era baixo, o que dificultava também as chances de inserção no mercado de trabalho urbano (Zago, 2016). Os planos para o futuro incluíam independência financeira, e para tal almejavam cursar ensino superior, em área correlata ao que aprenderam, ou se habilitarem em outras campos como administração, zootecnia ou direito, fazer mestrado ou especialização, formar família e ser autônomo:

Se me mudar para outra cidade vou fazer faculdade, não sei ainda de quê, quem sabe posso voltar para casa e trabalhar com os animais [...] se conseguir fazer medicina veterinária na UEMA. (EM24).

As mulheres detinham um nível educacional superior ao dos rapazes e manifestavam um desejo maior de deixar a atividade agrícola. No entanto, o medo, o desconforto, as exigências e a falta de oportunidade de trabalho na cidade acentuavam maior falta de vontade de sair do campo, pois aplicar no dia a dia o que aprenderam na escola também era uma opção cogitada:

[...] ficar em área próxima ou simplesmente trabalhar em casa (EM5).

Talvez pela forma como foram educadas nesta instituição, entre trabalhar na cidade e na área rural, de modo geral, a preferência pelo campo era quase maior: 
Pra quem gosta do campo mesmo é assim, é um trabalho muito prazeroso, é trabalho braçal, pesado, só que é prazeroso, é digno, é muito bom, porque só quem entende é quem mora lá e quem gosta [...] quando eu digo que gosto do campo, não quero sair, elas ficam “o que que eu vi?”, mas elas não entendem [...]. (EM18)

[...] porque quem mora no campo sabe, tem a tranquilidade, o trabalho ninguém precisa tá mandando e xingando e nem nada, você trabalhou pronto, não tem ninguém no seu pé, e além do mais trabalhando com respeito, com o meio ambiente, com a terra. (EM13)

Uma delas enfatiza a importância da produção de alimentos saudáveis, como disse:

Eu vou levar novas formas de produzir lá diferente, sem prejudicar a terra, porque agrotóxico prejudica muito a terra e tem várias outras formas de produzir alimentos saudáveis sem agrotóxicos, fazendo a horta na sua comunidade, na sua pequena terra, com conforto, tudo orgânico, tudo tirado dali mesmo, não precisa ir à cidade comprar, porque produz ali mesmo. (EM26)

A decisão de permanecer em casa muitas vezes se dava pelo desejo de ajudar a comunidade a produzir o próprio alimento de maneira saudável, gerando renda e autonomia alimentar, pois eles mostravam grande preocupação com os alimentos produzidos com adição de agrotóxico e os malefícios que vinham a ser causados a longo prazo, pois assimilaram esse conhecimento nas aulas. O desafio para eles era conscientizar a comunidade (especialmente os mais velhos) sobre os perigos do uso desses produtos nocivos e os impactos causados ao meio ambiente, substituindo a forma agressiva do plantio dos alimentos por uma mais sustentável e saudável, afinal sempre existia uma roça ou criação de animais nas comunidades e os donos, sem conhecimento científico/técnico, utilizavam métodos perigosos para a saúde na tentativa de uma produção mais rápida e com maior aproveitamento dos alimentos, conforme comentado nas entrevistas:

[... é uma experiência diferente da que eles costumavam ter lá, como exemplo do agrotóxico com fertilizante orgânico, a gente mesmo produz na própria comunidade, então é um conhecimento que eu vou passar pra eles, novo, que é uma melhoria para a comunidade, da vida deles, né? Porque hoje vocês sabem que a maioria das doenças que estão aparecendo são em relação à má alimentação, que a gente se alimenta de comidas com alimentos envenenados. (EM17)

[...] eи vou levar novas formas de produzir lá, diferentes, sem prejudicar a terra, porque agrotóxico prejudica muito a terra e tem várias outras formas de produzir alimentos saudáveis sem agrotóxicos, fazendo a horta na sua comunidade, na sua pequena terra, com conforto, tudo orgânico, tudo tirado dali mesmo, não precisa ir à cidade comprar, porque produz ali mesmo. (EM21)

[...] porque eles acreditam no que há muito tempo atrás já vem fazendo, mas eles não prestam atenção nos danos que no modo que eles estão fazendo tá causando na natureza [...] tá dando certo, mas não é o certo. Aí é sempre um desafio pra gente porque a gente é novo, ai eles "não, tu nasceu agora”, a gente tem que sempre tá caçando meios pra tá conseguindo convencer eles pra fazer do jeito certo. (EM26)

As informações alcançadas na CFR foram de extrema importância em vários aspectos: o conhecimento prévio de cuidados com animais foi fundamental para quem desejava fazer medicina veterinária; a qualidade das aulas favorecia o preparo para vestibulares; a convivência com pessoas de outras comunidades e com outros costumes possibilitava lidar melhor com as diferenças; as aulas práticas auxiliavam quem almejava ajudar em casa ou montar o próprio negócio. Todo aprendizado obtido na Casa Familiar Rural podia ser aproveitado em algum momento da vida profissional ou pessoal, conforme avaliação positiva feita pelos alunos:

Ajudou e muito [...] se eu tivesse estudado em uma escola tradicional, onde comecei meu ensino médio, com certeza que eu não tinha condição de passar na prova do ENEM ou no vestibular. (EM3)

Ensina muito a gente a viver no mundo [...]. Porque ensina a gente a trabalhar em equipe, a gente mexer com vários tipos de natureza [...] a gente morando desse jeito, a gente aprende muito a lidar com esse tipo de gente [...] isso aqui dá um alicerce muito bom pra gente, a saber lidar com todos os tipos de pessoas. (EM10) 
Existiam jovens, homens e mulheres, que lutavam por melhores condições de trabalho como agricultores no campo, já que se sentiam excluídos e marginalizados no processo de modernização nesse o trabalho (Silva, 2009). Ir para as cidades não estava em seus planos de continuidade profissional e de futuro de vida. O trabalho no campo não era considerado difícil, e sim uma questão de adaptação e de consciência sobre ele vir a ser um meio de sustento:

\section{É um trabalho como qualquer outro, é só a pessoa se adaptar àquele trabalho. (EM6).}

Isso e as relações de produção nas comunidades rurais, segundo Baruffi e Cimadon (1989), formavam valores e estruturavam uma organização social diferenciada do contexto urbano, exigindo, portanto, que as ações educativas fossem norteadas por características peculiares.

\section{Conclusão}

Neste artigo, objetivou-se descrever uma experiência de educação no campo, articulada ao currículo oficial para o nível médio de alunos inseridos em uma instituição de ensino agrícola, a Casa Familiar Rural de Bom Jesus da Selva (MA) realizada pelo Centro Popular de Cultura e Desenvolvimento / CPCD e examinar as perspectivas de presente e de futuro destes estudantes e suas percepções sobre as vivências na escola a partir da didática da pedagogia da alternância. A base educacional ali desenvolvida fez com que a relação trabalho-educação tivesse por fundamento a cooperação, a autogestão e o empoderamento para uma formação humanista, vinculando dialeticamente ensino formal e trabalho produtivo e inserindo a vida dos alunos na sala de aula.

Considerando as duas vertentes analisadas - Aprendendo a sonhar dentro da CFR-BJS e Aprendendo a viver fora da CFR - , foi possível concluir que a metodologia de educação popular para cidadania desenvolvida pela ONG, associada à pesquisa-ação, impactou de forma positiva os sonhos e as práticas dos alunos. O CPCD procurou conhecer, a priori, o modo como os jovens rurais viviam, sentiam e pensavam, como superavam os conflitos enfrentados diante da escolha profissional no futuro, para montar seu plano de atuação.

A estratégia didático-pedagógica empregada marcou a vida privada dos estudantes na construção de um projeto profissional de futuro. Uns reconheceram que, a partir do empoderamento pela prática da autonomia e liberdade, teriam chance de disputar uma disputa de vaga no vestibular, demonstrando o desejo de migrar para a cidade. Isto porque avaliaram favoravelmente o período que passaram na CFR-BJS e reconheceram que possuíam uma boa base para entrar na universidade e atingir um sonho de aprofundar aspectos da agricultura sustentável e da permacultura sem uso de agrotóxicos, ainda muito presente no manejo da terra no Maranhão, visando multiplicar esse saber nas áreas rurais. Eles narraram que a prática e o aperfeiçoamento do que foi aprendido em sala de aula poderia levá-los a aprimorar as técnicas ensinadas anteriormente por seus pais e trocar com eles o método teórico-prático dentro de cada realidade familiar e comunitária. Além disso, referiram que a relação de amizade com as pessoas da Casa foi fundamental no processo como um todo e, especialmente, para fortalecimento da autoestima de cada um e constituição de sua identidade para o mundo adulto.

Entretanto, como descreveram Visbiski \& Weirich Neto, (2004) sobre outras CFR estudadas, os ex-alunos reconheceram o preconceito da sociedade, especialmente a urbana, no que diz respeito a não valorização dos produtos agrícolas e orgânicos, ao descrédito do trabalho do campo, de ser um trabalho pouco rentável, presente na dificuldade do comércio, sem futuro e recompensas, pesado e sujo. Mesmo assim, parte deles expressou a vontade de continuar no campo, fosse trabalhando na terra ou abrindo um pequeno negócio, pois a educação popular e o convívio com colegas e educadores foram potentes a ponto de se sentirem com orgulho de serem camponeses, reafirmando o valor do aprendizado adquirido. 
A parceria com o CPCD e o financiamento obtido para a implantação dos projetos planejados puderam criar um espaço de estudo e trabalho favorável para os participantes no processo. Um ponto presente nas entrevistas ainda ficou por ser solucionado, as condições de deslocamento para ir e vir, uma vez que não havia transporte público, tanto para atividades técnicas (estágios permitidos) e para o lazer, questões estas pertinentes às políticas públicas municipais e estaduais do Maranhão. Ao final da formação na CFR, os jovens consideraram que o resultado foi positivo e que se sentiam empoderados ao compartilhar seu conhecimento com outras pessoas e poderem alcançar alguma independência financeira.

A pedagogia da alternância realiza-se de formas diferentes em cada CFR, dependendo dos sujeitos que a executam, dos contextos locais, dos limites concretos da realidade de cada território e, sobretudo, das concepções teóricas que organizam essas práticas em cada ambiente. No entanto, com a ajuda da educação popular e da pesquisa-ação conduzida pelo CPCD, a CFR-BJS, conseguiu tornar-se um exemplo que superou a fragmentação de conteúdo do ensino médio para o jovem do campo, não se limitando a ensinar uma realidade descolada da vida de seus alunos e, sim, compartilhando suas vivências para dentro do ambiente escolar.

Desse modo, o espaço possibilitou a inter-relação da formação teórica com a prática em um processo transdisciplinar de saberes socialmente compartilhados para atingir sonhos, desejos e expectativas de vida de grupo social.

\section{Referências}

Brandão, C. R. (1984). Casa de escola: cultura camponesa e educação rural. (Papirus, Ed.). Campinas.

Brasil. (2009). Parâmetros Curriculares Nacionais: Ensino Médio. Brasília.

Brasil. Lei no 12.852/13 (2013). http://www.planalto.gov.br/ccivil03/Ato20112014/2013/Lei/L12852.htm.

Brasil, I. (2020). Características da população e dos domicílios. https://www.ibge.gov.br/estatisticas/sociais/populacao/9109-projecao-dapopulacao.html?=\&t=o-que-e.

Braun, V., \& Clarker, G. (2014). Not Just for Beginners - A Review of Successful Qualitative Research: A Practical Guide for Beginners. The Qualitative Report, (May). https://doi.org/10.46743/2160-3715/2014.1206

Gadotti, M. (2003). Boniteza de um sonho: ensinar e aprender com sentido. (FEEVALE, Ed.). Novo Hamburgo.

Gimonet, J.-C. (2007). Praticar e compreender a pedagogia da alternância dos CEFFAs. (Vozes, Ed.). Petropolis.

Granereau, A. (1968). Le Livre de Lauzun: Une histoire de premières Maison familiales rurales. (L'Harmattan., Ed.). Paris.

Minayo, M. C. S. (2016). Pesquisa social: teoria, método e criatividade. (Editora Vozes, Ed.), Minayo, M.C.S (Org.) Pesquisa Social: teoria,método e criatividade (34th ed.). Petropolis.

Nosella, P. (2014). Educação no campo: origens da pedagogia da alternância no Brasil. (EDUFES., Ed.).

Parreira, L. C. A. (2014). Interfaces entre a gestão social e a educação: estudo de caso no centro popular de cultura e desenvolvimento - CPCD. PUC-SP.

Pizzinato, A., Petracco, M. M., Hamann, C., Cé, J. P., \& Rosa, E. N. (2017). Juventude feminina do meio rural: sentidos sobre educação e perspectivas sobre futuro. Psicologia Escolar e Educacional, 21(1), 41-51. https://doi.org/10.1590/2175-3539201702111066

Rocha, S. (2018). Escola como agente de transformação do território: comunidades rurais criam centros de excelência em educação no campo. https://educacaoeterritorio.org.br/experiencias/comunidade-rurais-criam-centros-de-excelencia-em-educacao-no-campo/

Rocha, S., Coutinho, V. L., Monteiro, C. B., \& Loyola, C. M. D. (2021). Projeto cuidadores em saúde: um relato de experiência. Research, Society and Development, 10(15), e09101522639. https://doi.org/10.33448/rsd-v10i15.22639

Saggese, E.; Leite, L. C. (2011). Da clínica à reabilitação psicossocial: manual de saúde mental de crianças e adolescentes. In IPUB/UFRJ (Ed.), Cadernos IPUB [online]. Rio de Janeiro. https://www.ipub.ufrj.br/cadernos-ipub-da-clinica-a-reabilitacao-psicossocial.

Silva, L. H. (2009). Centros familiares de formação por alternância: avanços e perspectivas na Construção da educação do Campo. Cadernos de Pesquisa: Pensamento Educacional, 4(8), 270-290.

Sinhoratti, F. (2015). As Casas Familiares Rurais e a Continuidade do Processo Formativo dos alunos egressos. Universidade Estadual do Oeste do Paraná/ UNIOESTE.

Troian, A., Dalcin, D., Oliveira, S. V., \& Troian, A. (2011). Jovens e a tomada de decisão entre permanecer ou sair do meio rural: um estudo de caso. Revista de Extensão e Estudos Rurais, 1(2), 349-374. 
Research, Society and Development, v. 10, n. 16, e374101623888, 2021

(CC BY 4.0) | ISSN 2525-3409 | DOI: http://dx.doi.org/10.33448/rsd-v10i16.23888

Visbiski, V. N., \& Weirich Neto, P. H. (2004). Casa Familiar Rural: uma Escola Diferente. Revista Extensão Rural.

Weisheimer, N. (2005). Juventudes rurais: mapa de estudos recentes.

Zago, N. (2016). Migração rural-urbana, juventude e ensino superior. Revista Brasileira de Educação, 21(64), 61-78. https://doi.org/10.1590/S141324782016216404 